\title{
Retraction Note to: Mosquito larvicidal properties of silver nanoparticles synthesized using Heliotropium indicum(Boraginaceae) against Aedes aegypti, Anopheles stephensi, and Culex quinquefasciatus (Diptera: Culicidae)
}

\author{
Kaliyan Veerakumar ${ }^{1} \cdot$ Marimuthu Govindarajan $^{1} \cdot$ Mohan Rajeswary $^{1}$ • Udaiyan Muthukumaran ${ }^{1}$
}

Published online: 29 March 2021

(C) Springer-Verlag GmbH Germany, part of Springer Nature 2021

Retraction Note to: Parasitol Res (2014) 113:2363-2373

https://doi.org/10.1007/s00436-014-3895-8

The Editors-in-Chief have retracted this article because it shows significant overlap with previously published articles by the same authors (Veerakumar et al., 2013, 2014). Additionally, Fig. 3 of this article appears to be identical to Fig. 3 in (Veerakumar et al., 2014). The Editors-in-Chief therefore no longer have confidence in the reliability of the data reported in the article. None of the authors agree to this retraction.

\section{References}

Veerakumar K, Govindarajan M, Rajeswary M (2013) Green synthesis of silver nanoparticles using Sida acuta (Malvaceae) leaf extract against Culex quinquefasciatus, Anopheles stephensi, and Aedes aegypti (Diptera: Culicidae). Parasitol Res 112:4073-4085. https:// doi.org/10.1007/s00436-013-3598-6

Veerakumar K, Govindarajan M, Rajeswary M, Muthukumaran U (2014)Low-cost and eco-friendly green synthesis of silver nanoparticles using Feronia elephantum (Rutaceae) against Culex quinquefasciatus, Anopheles stephensi, and Aedes aegypti (Diptera: Culicidae). Parasitol Res 113:1775-1785. https://doi.org/ 10.1007/s00436-014-3823-y

Publisher's note Springer Nature remains neutral with regard to jurisdictional claims in published maps and institutional affiliations.

The online version of the original article can be found at https://doi.org/ 10.1007/s00436-014-3895-8

Marimuthu Govindarajan

drgovindzoo@yahoo.com

1 Unit of Vector Biology and Phytochemistry, Department of Zoology, Annamalai University, Annamalainagar, Tamilnadu 608002, India 